\title{
Utilidad de la citología en el diagnóstico y manejo de tumores renales y perirrenales del adulto
}

\author{
Jiménez Heffernan JA*, González-Peramato P.*, Vicandi B.**, López Ferrer P**, \\ Serrano $\mathrm{A}^{* * *}$, Pérez Campos $\mathrm{A}^{*}$, Viguer $\mathrm{JM}^{* *}$. \\ *Servicio de Anatomía Patológica, Hospital Universitario de Guadalajara, **Servicio de Anatomía Patológica, \\ Hospital Universitario La Paz, Madrid, ***Servicio de Urología, Hospital Universitario de Guadalajara.
}

Actas Urol Esp. 2007;31(9):957-965

\section{RESUMEN}

UTILIDAD DE LA CITOLOGIA EN EL DIAGNÓSTICO Y MANEJO DE TUMORES RENALES Y PERIRRENALES DEL ADULTO

Introducción: El uso cada vez mas extendido de tumorectomías, nefrectomías parciales y tratamientos no quirúrgicos de tumores renales ha supuesto un renovado interés en el uso diagnóstico de la citología. Ya sea de forma preoperatoria, a través de la punción aspiración con aguja fina (PAAF), o durante el análisis intraoperatorio, la citología ofrece la posibilidad de un diagnóstico morfológico específico. En esta revisión se actualiza la información concerniente al valor diagnóstico de la citología de tumores renales.

Material y métodos: Se ha revisado la bibliografía relativa a las descripciones citológicas de masas renales. Para ello se ha procedido tanto a búsqueda computerizada en la base de datos Medline, como a búsqueda bibliográfica manual. Del mismo modo se incluye la experiencia de los autores tanto en la PAAF de estas lesiones como en el uso intraoperatorio de la citología.

Resultados: Entre las neoplasias con presentación citológica más característica destacan el carcinoma renal de células claras y el carcinoma renal papilar. El carcinoma cromófobo y el oncocitoma renal pueden mostrar similitudes, si bien la experiencia acumulada en los últimos años refleja que su diferenciación es posible en la mayoría de los casos. Para el diagnóstico de angiomiolipoma, carcinoma urotelial y metástasis en riñón, la información clínica y de imagen resulta es de gran interés para el patólogo. La integración de dichos datos suele permitir un diagnóstico específico.

Conclusión: En general, la citología refleja con fidelidad las características histológicas de las neoplasias renales, permitiendo en muchos casos un diagnóstico específico. Ante la cada vez más frecuente situación de "incidentaloma" renal, consideramos muy apropiado el uso diagnóstico de la citología. La naturaleza mínimamente invasiva de la PAAF y la posibilidad de realización de análisis citológico rápido durante estudios intraoperatorios ofrecen importante información para el manejo terapéutico de estos pacientes.

Palabras clave: Riñón. Neoplasia renal. Citología. PAAF.

ABSTRACT
USEFULNESS OF CYTOLOGY IN DIAGNOSIS AND MANAGEMENT OF RENAL AND PERIRENAL TUMORS IN ADULTS

Introduction: The use more and more extended of tumorectomy, partial nephrectomy and nonsurgical treatments of renal tumors has supposed a renewed interest in the diagnosis use of cytology. Whether during preoperative period, through the puncture aspiration with fine needle (PAAF), or during the intraoperative analysis, the cytology offers the possibility of a specific morphologic diagnosis. In this revision the information concerning the diagnostic value of the cytology in renal tumors is updated.

Material and methods: The references related to renal masses cytological descriptions has been reviewed. For this purpose we have searched both with computer in Medline data base and also manually. In the same way we include authors experience as much in the PAAF of these lesions as in the intraoperative use of the cytology.

Results: Between neoplasias with more cytological typical presentation are the clear cell renal and papillary carcinomas. The chromophobe and oncocytoma can show similarities, although the accumulated experience in the last years reflects that its differentiation is possible in most of the cases. For the diagnosis of angiomyolipoma, urothelial carcinoma and kidney metastasis, the clinical and image information are of great interest for the pathologist. The integration of these data usually allows a specific diagnosis.

Conclusion: Generally, cytology reflects with accuracy the histological characteristics of renal neoplasias, allowing in many cases a specific diagnosis. We consider much appropriated the use of cytology, due to the more and more frequent situation of "incidentaloma". The PAAF minimum invasive nature and the possibility of performing a fast cytological analysis during intraoperative studies offer important information for the therapeutic management of these patients.

Keywords: Kidney. Renal neoplasms. Cytology. Fine needle aspiration. 
$\mathrm{E}_{\mathrm{P}}^{\mathrm{n}}$ los primeros años de su introducción, la punción aspiración con aguja fina (PAAF) de lesiones renales fue utilizada con mucha frecuencia con objeto de confirmar el diagnóstico de quiste renal simple ${ }^{1,2}$. La posterior mejoría en las técnicas de imagen relegó parcialmente el papel de la PAAF. Su uso quedó limitado a tumores radiológicamente atípicos, o bien a aquellos en los que se planteaba embolización o irradiación preoperatoria y en los que el tumor era inoperable o la nefrectomía estaba contraindicada. En el caso de metástasis, afectación por linfoma o angiomiolipoma, la PAAF ha sido especialmente valiosa reduciendo el número de nefrectomías innecesarias $^{1-8}$. Durante los últimos años hemos asistido a un renovado interés por el uso de la citología en el diagnóstico de masas renales. Esto se debe a tres factores fundamentales: 1) el reconocimiento de la diversidad de neoplasias renales y de su diferente comportamiento y agresividad; 2) el aumento en el número de estudios de imagen de la cavidad abdominal con la consiguiente detección de numerosos tumores renales asintomáticos; y 3) el perfeccionamiento y generalización de la cirugía renal conservadora ${ }^{9-11}$. La cirugía conservadora está especialmente indicada en el caso de pacientes con tumores de pequeño tamaño y de baja agresividad, sobre todo si son bilaterales o asientan en pacientes con un solo riñón. Para ello es útil conocer preoperatoriamente, y de la forma menos invasiva posible, la exacta naturaleza lesional. Es en este contexto donde la citología puede aportar una información determinante. Como prueba de este interés por la citología, cabe destacar que las últimas ediciones de los textos clásicos de anatomía patológica quirúrgica, así como de las monografías especializadas, incluyen imágenes y referencias a las características citológicas de estas neoplasias ${ }^{12,13}$. El material citológico lo podremos obtener de forma preoperatoria por PAAF o durante el acto quirúrgico, en forma de estudio intraoperatorio. El uso intraoperatorio de la citología es un complemento muy valioso a las habituales secciones histológicas en congelación. En estas últimas no siempre es posible diferenciar entre las variantes de carcinoma renal, oncocitoma o incluso angiomiolipoma. El análisis citológico complementa el estudio y es especialmente útil si la muestra remitida es de pequeño tamaño. Uno de los problemas a los que se enfrenta la PAAF guiada con control de imagen es el tamaño lesional, ya que la rentabilidad diagnóstica es menor conforme menor es el tamaño tumoral ${ }^{14,15}$. En estas situaciones la evaluación citológica en estudio intraoperatorio adquiere mayor relevancia.

En el presente estudio se revisa la capacidad diagnóstica de la citología con especial énfasis en aquellas entidades donde la información de la precisa naturaleza neoplásica es de utilidad en el manejo terapéutico del paciente. En base a lo anteriormente descrito, este contexto es cada vez más amplio (Tabla 1). No se pretende una descripción exhaustiva de la citología de estas lesiones, sino transmitir al urólogo lo que puede esperar de la PAAF o de la citología intraoperatoria de una masa renal, y cuales son las dificultades y limitaciones más frecuentes a las que se enfrenta el patólogo.

Tabla 1. Situaciones donde la información citológica es de especial utilidad en el manejo de una masa renal

Tumor pequeño

Tumor en paciente monorreno

Tumores bilaterales

Tumor grande irresecable

Sospecha de angiomiolipoma

Masa renal con metástasis

Sospecha de metástasis en riñón

\section{MATERIAL Y MÉTODOS}

Se ha revisado la bibliografía concerniente a las descripciones citológicas de masas renales con especial interés en aquellas entidades neoplásicas de reciente aparición y áreas de dificultad diagnóstica (Tabla 2). Para ello se ha procedido tanto a búsqueda computerizada en la base de datos Medline, como a búsqueda bibliográfica manual. Del mismo modo se incluye la experiencia de los autores (Hospitales Universitarios de Guadalajara y La Paz, Madrid) tanto en la PAAF de estas lesiones como en el uso intraoperatorio de la citología. Dado que con relativa frecuencia las masas suprarrenales pueden ser indistinguibles de una neoplasia renal se incluye una breve descripción de las mismas. Se ha seguido un 
Tabla 2

\begin{tabular}{|c|c|c|}
\hline Entidad & $\begin{array}{l}\text { Diagnóstico citológico } \\
\text { específico }\end{array}$ & Diagnóstico diferencial \\
\hline Angiomiolipoma & Posible & Carcinoma renal, sarcoma \\
\hline Oncocitoma & Posible & Carcinoma cromófobo \\
\hline Carcinoma renal de células claras & Fácil & Oncocitoma, metástasis \\
\hline Carcinoma renal papilar & Fácil & Carcinoma de células claras, adenoma renal \\
\hline Carcinoma renal cromófobo & Posible & Oncocitoma, carcinoma renal granular \\
\hline Carcinoma de conductos colectores & Posible-dificil & Metástasis, carcinoma renal de alto grado \\
\hline Carcinoma urotelial & Fácil-posible & Carcinoma renal de alto grado \\
\hline Neoplasias adrenales & Fácil-posible & Carcinoma renal \\
\hline Metástasis & Fácil-posible & Carcinoma renal de alto grado o de conductos colectores \\
\hline
\end{tabular}

esquema clásico comenzando con las neoplasias benignas, carcinoma de células renales (y sus variantes), carcinoma urotelial, neoplasias adrenales y finalmente metástasis. Únicamente se describen aquellos tumores relativamente frecuentes. Existe una larga lista de neoplasias que pueden afectar al riñón de una forma primaria y que dada la escasa experiencia existente (descripciones aisladas) no son mencionadas en esta revisión.

\section{RESULTADOS Y DISCUSIÓN}

Antes de revisar las características citológicas más destacadas de cada neoplasia es necesario destacar algunos hechos relevantes que son intrínsecos al diagnóstico citológico. El factor más determinante de la dificultad de diagnóstico no lo constituye el proceso de interpretación sino el que le precede: la obtención del material. La más frecuente y conocida de las neoplasias puede convertirse en un terrible reto diagnóstico si el material citológico del que se dispone es escaso. El patólogo debe tratar de dar un diagnóstico lo mas preciso posible y para ello debe disponer de un material apropiado. Un material citológico adecuado demanda un diagnóstico igualmente adecuado, sin embargo, no se puede realizar un diagnóstico citológico preciso cuando el material citológico es de mala calidad. Para minimizar el número de muestras citológicas defectuosas, o errores diagnósticos debidos a la escasez de material, es necesario contar con un equipo de urólogos, radiólogos y patólogos compenetrado y sensibilizado del valor de la citología. Basta que uno de estos tres ingredientes no funcione adecuadamente para que todo el proceso de diagnóstico se debilite. Que exista compenetración y armonía entre los profesionales involucrados no debe considerarse como algo excepcional y deseable sino como algo necesario. A las muchas dificultades del proceso de diagnóstico no debemos añadir ninguna otra.

\section{NEOPLASIAS BENIGNAS}

\section{Angiomiolipoma renal}

En la mayor parte de los casos, los estudios de imagen identifican el tejido adiposo de la neoplasia, permitiendo una alta sospecha diagnóstica. No obstante, existen tumores con presentación atípica o incluso carcinomas renales con componente adiposo que inducen a confusión ${ }^{16,17}$. Por ello la PAAF puede jugar un papel importante en la evaluación preoperatoria. La imagen citológica suele mostrar celularidad mesenquimal fusiforme, componente adiposo y participación variable de macrofágos y células inflamatorias (Fig. 1). El número de descripciones citológicas de esta neoplasia es amplio y puede considerarse como bien caracterizada $^{2,18-22}$. En ocasiones, el componente muscular liso adopta un aspecto epitelioide y puede mostrar pleomorfismo nuclear; esto puede inducir a un diagnóstico erróneo de carcinoma renal y constituye el mayor problema de diagnóstico diferencial ${ }^{23,24}$. En estos casos los estudios inmunocitoquímicos resultan de gran utilidad. La posibilidad de un sarcoma surge especialmente 


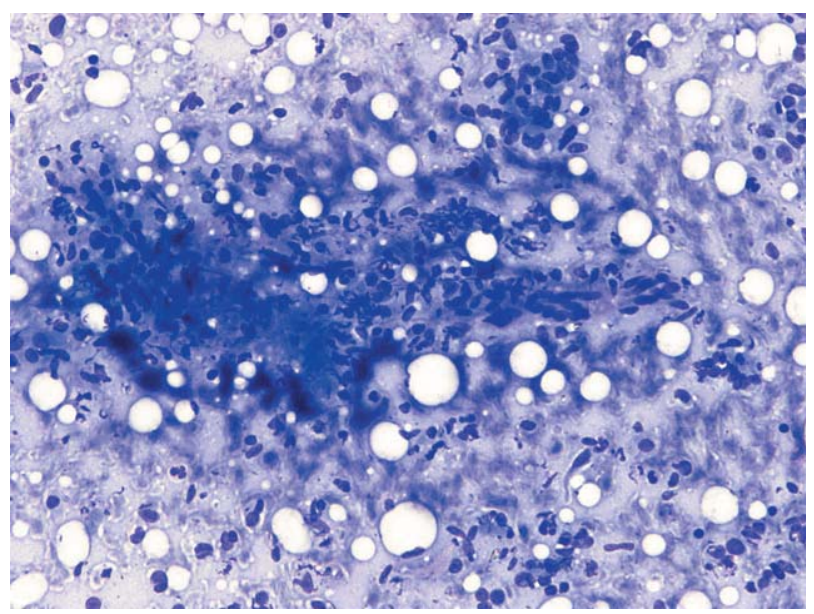

FIGURA 1. Angiomiolipoma renal. Grupo de células mesenquimales fusocelulares con componente adiposo $y$ presencia de células inflamatorias en el fondo del extendido.

en aquellos casos en los que los estudios de imagen no muestran relación directa con el riñón. Por lo tanto, y de forma rutinaria, cuando se evalúa una masa renal o perirrenal el patólogo debe considerar siempre la posibilidad de angiomiolipoma. La sospecha radiológica es de gran ayuda al diagnóstico citológico y el radiólogo o urólogo debe transmitir dicha información.

\section{Oncocitoma}

Su comportamiento benigno y relativa frecuencia ( $3 \%$ de los tumores renales) hace de él una de las neoplasias donde el diagnóstico preoperatorio es más deseable. La experiencia citológica empieza a ser muy amplia y refleja, en muchos casos, la posibilidad de un diagnóstico específico ${ }^{1,2,25-29}$. Citológicamente, el oncocitoma se dispone en forma de grupos monoplano y células sueltas de tamaño intermedio a grande con característico citoplasma amplio, de límites bien definidos, densamente teñido y de aspecto finamente granular. El núcleo es central, redondeado y es frecuente observar nucleolo, en general de pequeño tamaño (Fig. 2). Puede existir pleomorfismo nuclear. Debe tenerse en cuenta que pueden ser objeto de confusión con el carcinoma renal cromófobo y aquellos carcinoma renales en los que predominan las células granulares. En el oncocitoma, la población neoplásica y su citoplasma es muy homogénea, existiendo mayor variabilidad en el cromófobo y granular. La inmunoexpresión de citoqueratinas, vimentina, así

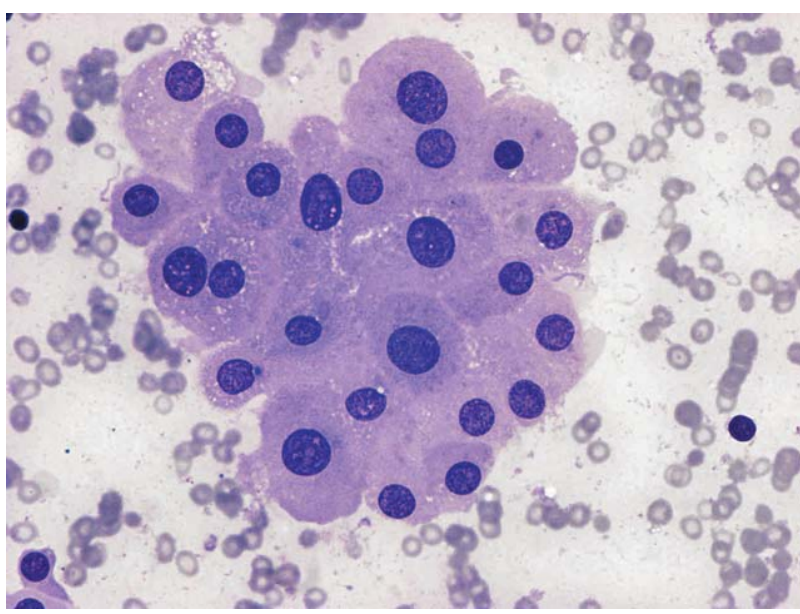

FIGURA 2. Oncocitoma renal. Grupo monocapa de células de citoplasma granular eosinófilo y núcleo central con nucléolo poco evidente.

como la detección de hierro coloidal ha demostrado su utilidad en material de citología. Dos estudios citológicos relevantes han descrito que la diferenciación entre oncocitoma y carcinoma cromófobo es posible en la mayoría de los $\operatorname{casos}^{28,29}$. Resulta imprescindible comunicar al patólogo datos clínicos y de imagen ya que pueden ser tan determinantes como la propia imagen citológica.

\section{CARCINOMA DE CÉLULAS RENALES Y SUS VARIANTES}

\section{Carcinoma de células renales, tipo células claras (convencional)}

Es la forma mas frecuente de carcinoma de células renales (70\%) y por tanto objeto de diagnóstico diferencial obligado con cualquier masa renal. Se caracteriza por la presencia de células neoplásicas de amplio citoplasma claro. Este aspecto "claro" se debe a la presencia de grandes cantidades de lípidos y glucógeno. Otra población celular, más escasa, se denomina de células granulares y en ocasiones constituye la mayor parte de la población tumoral. A diferencia de las células claras muestran un citoplasma eosinófilo, densamente teñido, de límites mal definidos. Cuando el material citológico es abundante el reconocimiento específico de carcinoma renal de células claras es sencillo, incluso en casos de metástasis en los que se desconoce la existencia de masa renal primaria ${ }^{2,30-32}$. Las células se disponen sueltas y en grupos, con frecuente presen- 
cia en estos últimos de delicado material estromal (a modo de membrana basal) (Fig. 3a). El citoplasma es amplio y vacuolado, y el núcleo en general pleomórfico, con nucleolo y pseudoinclusiones (Fig. 3b). También son frecuentes las estructuras vasculares capilares. Dentro de los carcinomas de células renales convencionales, cabe destacar tres variantes histológicas de especial interés:

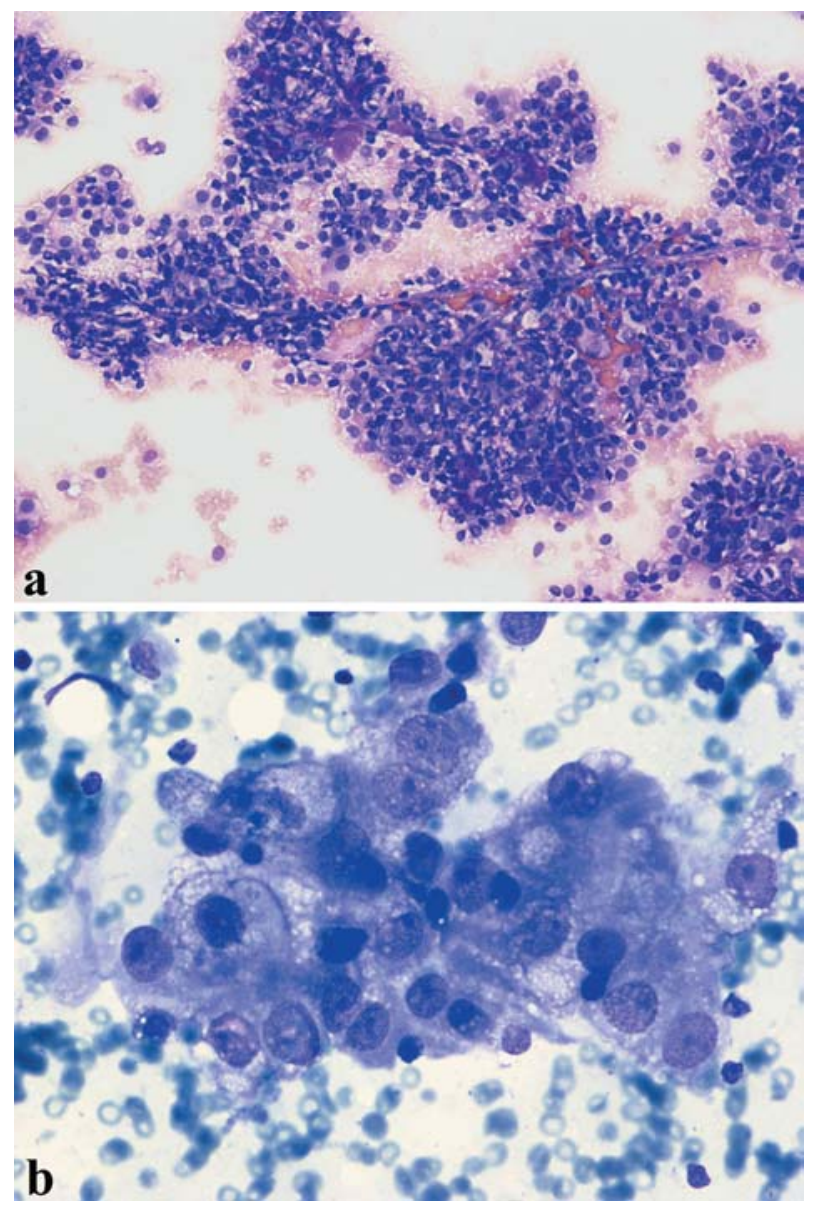

FIGURA 3. Carcinoma de células renales tipo células claras. a) Grupo de células neoplásicas con material estromal eosinófilo. b) Placa de células neoplásicas con citoplasma vacuolado y núcleo redondo con nucléolo prominente.

- Carcinoma de células renales, variante quística, multilocular: El diagnóstico de esta entidad puede resultar particularmente problemática y debe considerase, de forma obligada, en el diagnóstico diferencial de lesiones renales quísticas. Las características citológicas son similares a las del carcinoma renal de células claras, residiendo el problema de su reconocimiento en un adecuado muestreo del tumor. Esto es igualmente aplicable a la evaluación intraoperatoria donde el patólogo debe buscar las zonas más sólidas y de coloración anaranjada.

- Carcinoma de células renales variante sarcomatoide: Cualquier tipo histológico de carcinoma de células renales puede evidenciar áreas de crecimiento neoplásico fusocelular de patrón sarcomatoso. En general, dichas áreas son de alto grado citológico e implican mal pronóstico. Morfológicamente la lesión puede ser confundida con un sarcoma (Fig. 4). Por ello, ante toda neoplasia renal de patrón sarcomatoso debe considerarse la posibilidad de carcinoma renal ${ }^{33}$. Además, las dificultades pueden surgir cuando la neoplasia es de tamaño grande y se plantea la posibilidad de sarcoma retroperitoneal con afectación renal. Un muestreo amplio de la lesión así como la realización de estudios inmunohistoquímicos permiten un correcto diagnóstico en la mayor parte de los casos.

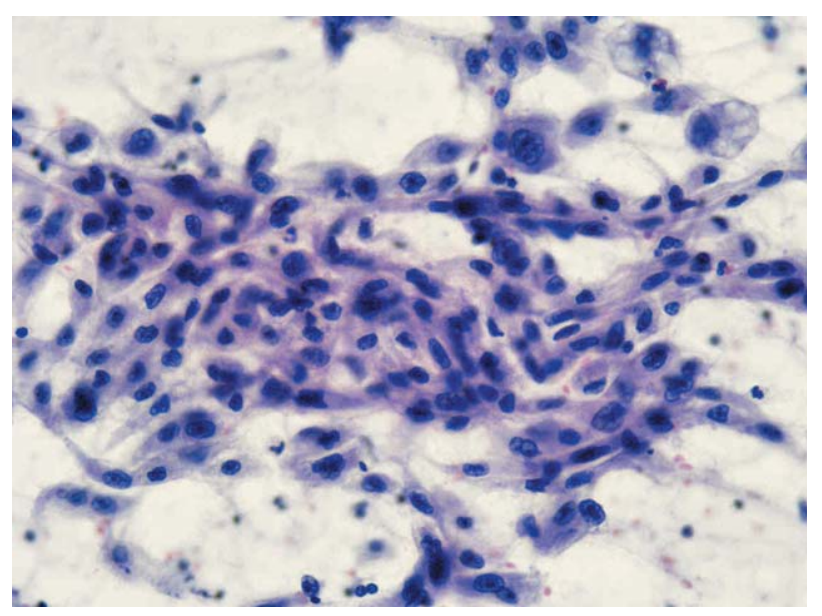

FIGURA 4. Carcinoma de células renales variante sarcomatoide. Grupo de células epiteliales fusocelulares y poligonales con escasa cohesividad y marcada atipia nuclear.

- Carcinoma de células renales tipo rabdoide: Se define como un carcinoma de células renales con presencia en variable cantidad de células neoplásicas de morfología rabdoide. Entre un 3 y un $7 \%$ de los carcinomas de células renales muestran celularidad rabdoide en cuantía significativa $^{34}$. Si bien existe poca experiencia con esta 
variante, parece implicar un peor pronóstico ${ }^{35}$. Citológicamente se caracteriza por un fenotipo celular rabdoide (células grandes de núcleo excéntrico y amplio citoplasma eosinófilo) que se entremezclan con células claras, lo que constituye la clave del diagnóstico ${ }^{36}$.

\section{Carcinoma de células renales tipo papilar}

Representan un 10-15\% de los carcinomas de células renales. Cuando son de pequeño tamaño resultan muy difíciles de distinguir del adenoma renal. Hoy se acepta que cualquier neoplasia papilar mayor de $0,5 \mathrm{cms}$. debe considerarse un carcinoma. El carcinoma papilar de riñón es una neoplasia de límites bien definidos, habitualmente encapsulada y de localización cortical. Por todo ello, cuando son de reducidas dimensiones se puede plantear un abordaje quirúrgico conservador. En lo referente a la citología, cabe destacar que es una de las variantes de carcinoma renal mejor caracterizadas. Destacan los fragmentos papilares, la abundante participación macrofágica y un fondo de los extendidos de aspecto "sucio" (Fig. 5). Con frecuencia, los macrófagos se disponen en íntima relación con las papilas e incluso en su interior. Las células neoplásicas son de tamaño intermedio, con variable vacuolización y hemosiderina intracitoplasmática. En general, el pleomorfismo nuclear no es intenso y son frecuentes las hendiduras nucleares. Estas características están bien recogidas en los distintos estudios citológicos publicados ${ }^{37-39}$. Es tam-

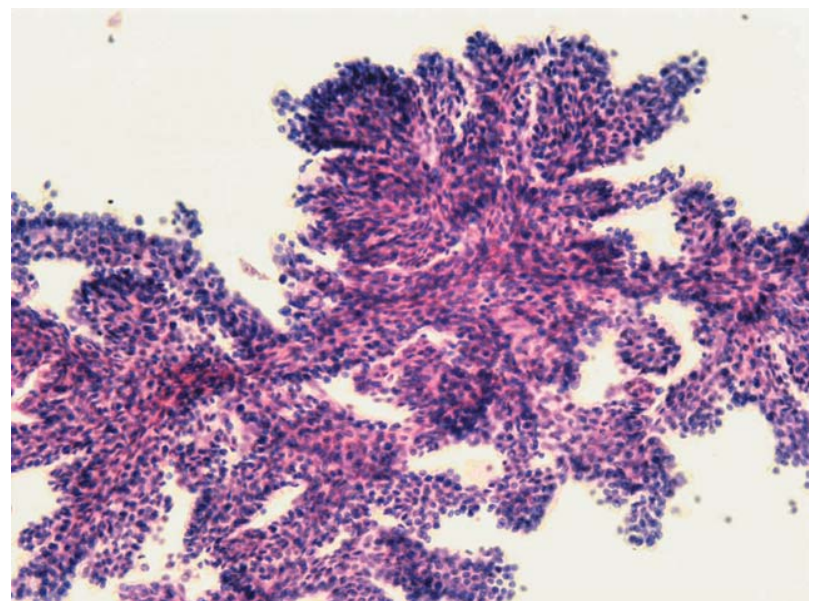

FIGURA 5. Carcinoma de células renales tipo papilar. Fragmento de estructuras papilares ramificadas con células pequeñas y monomorfas. bién la opinión de los autores que el carcinoma papilar es la variante de carcinoma de células renales con presentación citológica más característica y definitoria.

\section{Carcinoma de células renales tipo cromófobo}

Pocas entidades neoplásicas genito-urinarias han despertado tanto interés, en los últimos años, como lo ha hecho el carcinoma renal cromófobo. Probablemente se debe a que constituye una entidad bien definida desde la perspectiva morfológica, inmunohistoquímica y molecular. $\mathrm{Su}$ comportamiento, menos agresivo, también parece diferir del carcinoma renal convencional. Morfológicamente, puede ser objeto de confusión con el oncocitoma y con el carcinoma renal con predominio de células granulares. Precisamente, esta triada constituye uno de los retos diagnósticos de la citología neoplásica renal. El principal diagnostico diferencial del carcinoma cromófobo debe ser el oncocitoma pues esta es una neoplasia benigna. Si una neoplasia se encuentra en el límite de tamaño, el diagnóstico de oncocitoma apoyará la decisión de nefrectomía parcial mientras que el de carcinoma favorecerá la realización de nefrectomía radical. Este problema queda reflejado en la literatura citológica, que se muestra optimista en cuanto al reconocimiento específico del carcinoma cromófobo, aunque las publicaciones centradas en el carcinoma cromófobo son todavía escasas ${ }^{28,29,40-42}$. En nuestra experiencia con siete casos el carcinoma cromófobo muestra una celularidad más pleomórfica y citoplasma más heterogéneo que el del oncocitoma así como frecuente binucleación y halos perinucleares (Fig. 6). Si se dispone de material suficiente los estudios inmunocitoquímicos pueden ser de gran utilidad. Con todo, la relativa rareza de esta variante neoplásica hace difícil adquirir una experiencia citológica lo suficientemente amplia, por lo que todavía debemos esperar a la publicación de series con mayor casuística.

\section{Carcinoma de células renales de los \\ conductos colectores}

Suponen menos del 1\% de las neoplasias epiteliales renales del adulto. Parecen originarse en los conductos colectores, siendo habitual una localización medular del tumor y la coexistencia 


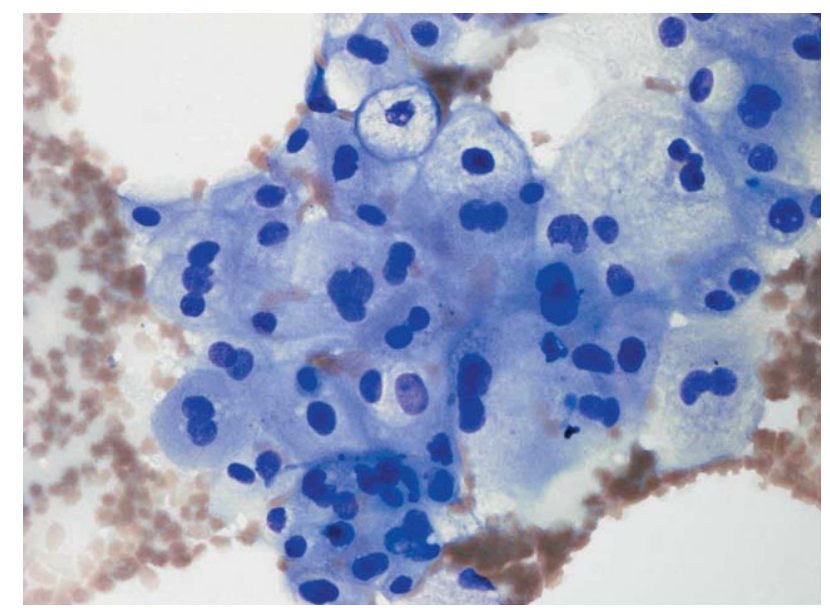

FIGURA 6. Carcinoma de células renales tipo cromófobo. Placa de células de carcinoma en la que algunas muestran citoplasma muy amplio con frecuentes imágenes de bi $y$ multinucleaciones.

con áreas de displasia ("in situ") de dichos conductos. La forma más clásica de esta neoplasia crece formando túbulos y papilas en el seno de un estroma densamente colagenizado. Esta imagen se refleja en la citología, que difiere considerablemente del resto de carcinomas de células renales ${ }^{43-46}$. El patrón es más propio de un adenocarcinoma de tipo ductal con alto grado. En citología el estroma colagenizado se observa como fragmentos de estroma hialino. Resulta fácil imaginar que las metástasis renales constituyen el diagnóstico diferencial obligado.

\section{CARCINOMA UROTELIAL (TRANSICIONAL)}

Cuando afecta a región pielo-calicial puede infiltrar el parénquima renal, determinando la aparición de una masa renal. Estas neoplasias uroteliales infiltrantes suelen ser pobremente diferenciadas, con escasas papilas, alto grado citológico y frecuente diferenciación escamosa. El aspecto citológico es el de un carcinoma de células grandes, con moderada cantidad de citoplasma denso y núcleo pleomórfico (Fig. 7) ${ }^{47,48}$. Habitualmente son fáciles de diferenciar del carcinoma convencional de células renales y sus variantes. La presencia de diferenciación escamosa así como su relación con el sistema pielo-calicial son importantes claves para su reconocimiento específico.

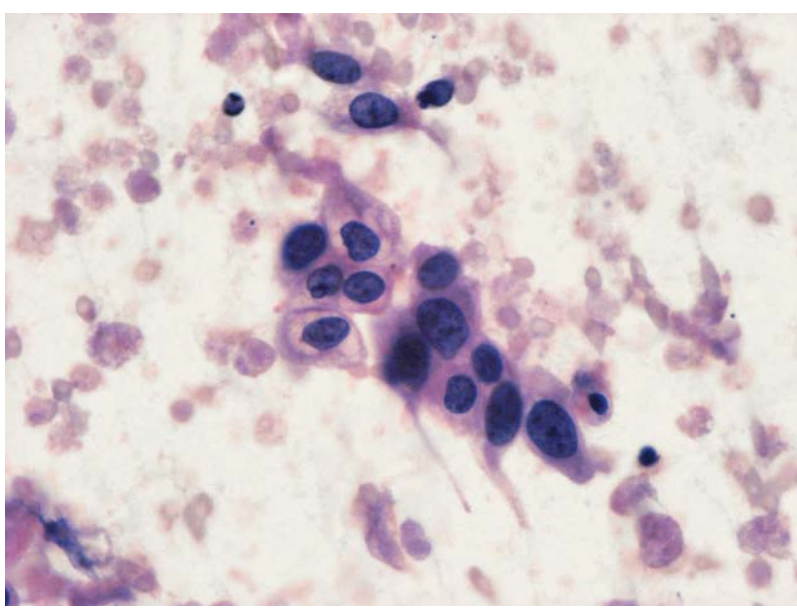

FIGURA 7. Carcinoma Urotelial. Placa de células de citoplasma denso y núcleo hipercromático e irregular.

\section{NEOPLASIAS SUPRARRENALES}

Cuando son de reducidas dimensiones se suelen reconocer fácilmente como independientes del parénquima renal. Por el contrario, las grandes neoplasias adrenales que ocultan o infiltran el polo renal superior pueden confundirse con un carcinoma renal ("hipernefroma"). En estos casos el tratamiento quirúrgico es similar, por lo que su diferenciación preoperatoria no es crítica. Los extendidos citológicos de las lesiones de corteza suprarrenal (adenomas y carcinomas) suelen evidenciar un fondo lipídico, microvacuolado y células con una moderada cantidad de citoplasma igualmente microvavuolado ${ }^{49,50}$. La atipia es menor a la del carcinoma renal convencional. El feocromocitoma no funcionante también debe ser considerado en el diagnóstico diferencial. Su pleomorfismo y amplio citoplasma puede remedar al carcinoma renal. A diferencia de éste no muestra vacuolización del citoplasma, ni material estro$\mathrm{mal}^{51}$. De nuevo, los estudios inmunocitoquímicos pueden resultar determinantes.

\section{METÁSTASIS RENALES}

La sospecha de metástasis en riñón ha sido, y continua siendo, una de las indicaciones clásicas de PAAF de una masa renal. Los antecedentes más frecuentes son carcinoma de pulmón y mama, melanoma, linfoma, carcinoma renal contralateral y neoplasias del tubo digestivo, ovario y testículo. Entre los linfomas hay que destacar el linfoma mediastínico de células grandes que muestra una peculiar afinidad por metastatizar en riñón. Habitualmente, 
el manejo de estos pacientes recae más en el oncólogo que en el urólogo. La diferenciación, por técnicas de imagen, entre neoplasia primitiva $y$ metástasis puede resultar problemática. La mayoría de las metástasis son múltiples, bilaterales y de limites bien definidos. Cuando son únicas surge la posibilidad de neoplasia renal primaria. La citología tiene un gran valor en el reconocimiento de la naturaleza metastásica de estas lesiones ${ }^{52}$. Esto es especialmente cierto si el patólogo es informado del antecedente neoplásico del paciente.

\section{CONCLUSIONES}

En general, la citología refleja con fidelidad las características histológicas de las neoplasias renales, permitiendo en muchos casos un diagnóstico específico. Las áreas de dificultad diagnóstica de la citología suelen ser similares a las de la histopatología $y$, al igual que aquí, la inmunocitoquímica puede ser de gran de utilidad. La naturaleza mínimamente invasiva de la PAAF y la posibilidad de realización de un análisis citológico rápido durante estudios intraoperatorios ofrecen al urólogo y al oncólogo importante información para el manejo terapéutico de los pacientes con masas renales. La citología no debe ser entendida como una forma menor de diagnóstico morfológico sino como una de las más potentes herramientas de diagnóstico preoperatorio. En este sentido, y ante la cada vez más frecuente situación de "incidentaloma" renal, consideramos que el futuro de la PAAF renal como método diagnóstico de pacientes con masas renales es prometedor, o así debería serlo.

\section{REFERENCIAS}

1. McKee GT. The kidney and retroperitoneal tissues. In: Gray W, McKee GT (eds.). Diagnostic Cytopathology. Churchill Livingstone; 2003:pp. 449-497.

2. Orell SR, Sterrett GF, Whitaker D. Fine needle aspiration cytology. Fourth edition. Elsevier, 2005:pp. 337-360.

3. Leiman G. Audit of fine needle aspiration cytology of 120 renal lesions. Cytopathology 1990;1(2):65-72.

4. Niceforo J, Coughlin BF. Diagnosis of renal cell carcinoma: value of fine needle aspiration cytology in patients with metastases or contraindications to nephrectomy. AJR Am J Roetgenol 1993;161(6):1303-1305.

5. Kelley CM, Cohen MB, Raab SS. Utility of fine-needle aspiration biopsy in solid renal masses. Diagn Cytopathol 1996; 14(1):14-19.

6. Troung LD, Todd TD, Dhurandhar B, Ramzy I. Fine-needle aspiration of renal masses in adults: analysis of results and diagnostic problems in 108 cases. Diagn Cytopathol 1999; 20(6):339-349.
7. Zardawi IM. Renal fine needle aspiration cytology. Acta Cytol. 1999 Mar-Apr;43(2):184-190.

8. Johnson PT, Nazarian LN, Feld RI, Needleman L, Lev-Toaff AS, Segal SR et al. Sonographically guided renal mass biopsy: indications and efficacy. J Ultrasound Med 2001; 20(7):749-53.

9. Joniau S, Vander Eeckt K, Van Poppel H. The indications for partial nephrectomy in the treatment of renal cell carcinoma. Nat Clin Pract Urol 2006;3(4):198-205.

10. Martinez-Piñeiro JA, Lopez-Tello J, Martinez-Piñeiro L, de la Peña JJ. Cirugía conservadora de parénquima en neoformaciones renales. Actas Urol Esp 2000;24(2):94-119.

11. Mitchell RE, Gilbert SM, Murphy AM, et al. Partial nephrectomy and radical nephrectomy offer similar cancer outcomes in renal cortical tumors $4 \mathrm{~cm}$ or larger. Urology 2006;67(2):260-264

12. Rosai J. Rosai and Ackerman's surgical pathology. Ninth edition. Mosby, Edinburgh, 2004:pp 1163-1316.

13. Murphy WM, Grignon DJ, Perlman EJ. Tumors of the kidney, bladder, and related urinary structures. Atlas of tumor pathology. American Registry of Pathology, Washington, DC , Fourth series, 2004.

14. Brierly RD, Thomas PJ, Harrison NW, et al. Evaluation of fine-needle aspiration cytology for renal masses. BJU Int 2000;85(1): 14-18.

15. Campbell SC, Novick AC, Herts B, Fischler DF, Meyer J, Levin HS, Chen RN. Prospective evaluation of fine needle aspiration of small, solid renal masses: accuracy and morbidity. Urology 1997;50(1):25-29.

16. Kim JK, Park SY, Shon JH, Cho KS. Angiomyolipoma with minimal fat: differentiation from renal cell carcinoma at biphasic helical CT. Radiology 2004;230(3):677-684.

17. Roy C, Tuchmann C, Lindner V, Guth S, Vasilescu C, Saussine C, et al.. Renal cell carcinoma with a fatty component mimiking angiomyolipoma on $\mathrm{CT}$. $\mathrm{Br} \mathrm{J}$ Radiol. 1998;71(849):977-979.

18. Glenthoj A, Partoft S. Ultrasound-guided percutaneous aspiration of renal angiomyolipoma. Report of two cases diagnosed by cytology. Acta Cytol 1984;28(3):265-268.

19. Bonzanini M, Pea M, Marignoni G, Zamboni G, Capelli P, Bernardello F, et al. Preoperative diagnosis of renal angiomyolipoma: fine needle aspiration cytology and immunocytochemical characterization. Pathology 1994;26 (2): $170-175$

20. Tallada N, Martinez S, Raventos A. Cytologic study of renal angiomyolipoma by fine-needle aspiration biopsy: report of four cases. Diagn Cytopathol 1994;10(1):37-40.

21. Wadih GE, Raab SS, Silverman JF. Fine needle aspiration cytology of renal and retroperitoneal angiomyolipoma. Report of two cases with cytologic findings and clinicopathologic pitfalls in diagnosis. Acta Cytol 1995;39(5):945950.

22. Granter SR, Renshaw AA. Cytologic analysis of renal angiomyolipoma: a comparison of radiologically classic and challenging cases. Cancer 1999;87(3):135-140.

23. Mojica WD, Jovanoska S, Bernacki EG. Epithelioid angiomyolipoma: appearance of fine-needle aspiration- report of a case. Diagn Cytopathol 2000;23(3):192-195.

24. Hino A, Hirokawa M, Takamura K, Sano T. Imprint cytology of epithelioid angiomyolipoma in a patient with tuberous sclerosis. A case report. 2002;46(3):545-549.

25. Alanen KA, Tyrkko JES, Nurmi MJ. Aspiration biopsy cytology of renal oncocytoma. Acta Cytol 1985;29(5):859862 . 
26. Cochand-Priollet B, Rothschild E, Chagnon S, Nezelof C, Debure A, Galian A. Renal oncocytoma diagnosed by fineneedle aspiration cytology. Br J Urol 1988;61(6):534-535.

27. Caputo V, Repetti ML, Bordoni V, Radice F. Preoperative diagnosis of renal oncocytoma by fine needle aspiration. Cytopathology 1996;7(5):366-371.

28. Wiatrowwska BA, Zakowski MF. Fine-needle aspiration biopsy of chromophobe renal cell carcinoma and oncocytoma: comparison of cytomorphologic features. Cancer 1999;87(3):161-167.

29. Liu J, Fanning CV. Can renal oncocytomas be distinguished from renal cell carcinoma on fine-needle aspiration specimens?. A study of conventional smears in conjunction with ancillary studies. Cancer Cytopathol 2001;93(6): 390-397.

30. Franzén S, Brehmer-Andersson E. Cytologic diagnosis of renal cell carcinoma. Prog Clin Biol Res 1982;100:425432 .

31. Linsk JA, Franzén S. Aspiration cytology of metastatic hypernephroma. Acta Cytol 1984;28(3):250-260.

32. Saleh H, Masood S, Wynn G, Assaf A. Unsuspected metastatic renal cell carcinoma diagnosed by fine needle aspiration biopsy. A report of four cases with immunocytochemical contributions. Acta Cytol 1994;38(4):554-561.

33. Auger M, Katz RL, Sella A, Ordóñez NG, Lawrence DD, Ro JY. Fine needle aspiration cytology of sarcomatoid renal cell carcinoma: a morphologic and immunocytchemical study of 15 cases. Diagn Cytopathol 1993;9(1):46-51.

34. Gökden N, Nappi O, Swanson PE, Pfeifer JD, Vollmer RT, Wick MR et al. Renal cell carcinoma with rhabdoid features. Am J Surg Pathol 2000;24(10):1329-1338.

35. Kuroiwa K, Kinoshita Y, Shiratsuchi H, Oshiro Y, Tamiya $\mathrm{S}$, Oda Y, et al. Renal cell carcinoma with rhabdoid features: an aggressive neoplasm. Histopathology 2002;41(6): 538-548.

36. Pérez F, Jiménez-Heffernan JA, Pérez-Campos A, Viguer JM. Cytologic features of renal cell carcinoma with rhabdoid features. Cytopathology 2005; 15:237-238.

37. Flint A, Cookingham C. Cytologic diagnosis of the papillary variant of renal-cell carcinoma. Acta Cytol 1987;31(3):325329.

38. Dekmezian R, Sneige N, Shaab N. Papillary renal-cell carcinoma: fine needle aspiration of 15 cases. Diagn Cytopathol 1991;7(2):198-203.

39. Granter SR, Perez-Atayde AR, Renshaw AA. Cytologic analysis of papillary renal cell carcinoma. Cancer Cytopathol 1998;84(5):303-308.

40. Akhtar M, Ashraf Ali M. Aspiration cytology of chromophobe cell carcinoma of the kidney. Diagn Cytopathol 1995; 13(4):287-294.
41. Granter SR, Renshaw AA. Fine needle aspiration of chromophobe renal cell carcinoma. Analysis of six cases. Cancer 1997;81(2): 122-128.

42. Renshaw AA, Lee KR, Madge R, Granter SR. Accuracy of fine needle aspiration in distinguishing subtypes of renal cell carcinoma. Acta Cytol 1997;41(4):987-994.

43. Layfield LJ. Fine needle aspiration cytology of renal collecting duct carcinoma. Diagn Cytopathol 1994;11(1):74-78.

44. Caraway NP, Wojcik EM, Katz RL, Ro JY, Ordonez NG. Cytologic findings of collecting duct carcinoma of the kidney. Diagn cytopathol 1995;13(4):304-309.

45. Ono K, Nishino E, Nakamine H. Renal collecting duct carcinoma. Report of a case with cytologic findings on fine needle aspiration. Acta Cytol 2000;44(3):380-384.

46. Sarode VR, Islam S, Wooten D, Watumull LM, Molberg K, Ashfaq R. Fine needle aspiration cytology of collecting duct carcinoma of the kidney: report of a case with distinctive features and differential diagnosis. Diagn Cytopathol 2004;48(6):843-848.

47. Santamaría M, Jáuregui I, Urtasu F, Bertol A. Fine needle aspiration biopsy in urothelial carcinoma of the renal pelvis. Acta Cytol 1995;39(3):443-448.

48. Nguyen GK, Schumann GB. Needle aspiration cytology of low-grade transitional cell carcinoma of the renal pelvis. Diagn Cytopathol 1997;16(5):437-441.

49. De Agustin P, López-Rios F, Alberti N, Pérez-Barrios A. Fine-needle aspiration biopsy of the adrenal glands: a tenyear experience. Diagn Cytopathol 1999;21(2):92-97.

50. Yang B, Ali SZ, Rosenthal DL. CD10 facilitates the diagnosis of metastatic renal cell carcinoma from primary adrenal cortical neoplasm in adrenal fine-needle aspiration. Diagn Cytopathol 2002;27(3):149-152.

51. Jiménez-Heffernan JA, Vicandi B, López-Ferrer P, Gonzalez-Peramato P, Perez-Campos A, Viguer JM. Cytologic features of pheochromocytoma and retroperitoneal paraganglioma: a morphologic and immunohistochemical study of 13 cases. Acta Cytol 2006;50(4):372-378.

52. Giashuddin S, Cangiarella J, Elgert P, Levine PH. Metastases to the kidney: eleven cases diagnosed by aspiration biopsy with histological correlation. Diagn Cytopathol 2005;32:325-329.

Correspondencia autor: Dr. José A. Jiménez Heffernan Servicio de Anatomía Patológica.

Hospital Universitario de Guadalajara

Donantes de sangre s/n - 19002 Guadalajara

E-mail autor: jjheffernan@yahoo.com

Información artículo: Original - Biopsia intraoperatoria 